\title{
Estudo in silico de compostos fenólicos isolados de Inga laurina
}

\author{
In silico study of phenolic compounds isolated from Inga laurina \\ Estudio in silico de compuestos fenólicos aislados de Inga laurina
}

Recebido: 11/01/2022 | Revisado: 15/01/2022 | Aceito: 22/01/2022 | Publicado: 24/01/2022

Cristian Kallahan Silva Chagas

ORCID: https://orcid.org/0000-0001-6509-7470

Universidade Federal do Pará, Brasil E-mail: criskallahan@gmail.com

Camilla Eduarda Lima Rolim

ORCID: https://orcid.org/0000-0003-1679-2922

Universidade Federal do Pará, Brasil

E-mail: rolimcamilla@gmail.com

Hanna Patricia dos Santos Martins

ORCID: https://orcid.org/0000-0002-3486-4048

Universidade Federal do Pará, Brasil

E-mail: hannamartins77@gmail.com

Maria Fani Dolabela

ORCID: https://orcid.org/0000-0003-0804-5804

Universidade Federal do Pará, Brasil

E-mail: fanidolabela20@gmail.com

\begin{abstract}
Resumo
A Inga laurina Willd, pertence à família Fabaceae, utilizada popularmente contra infecções fúngicas, já foram isolados vários compostos flavônicos de todas as suas partes, porém são poucos os estudos que avaliam as propriedades farmacocinéticas, toxicológicas e suas atividades biológicas destas, devido isso, esse artigo tem como objetivo avaliar tais propriedades de compostos flavônicos isolados das folhas de Inga laurina. Foi utilizado o software ChemSketch, as bases de dados PreADMET, PASS online e Mcule. Os resultados demonstraram que a Galocatequina- $(4 \alpha-8)-4-O-$ metilgalocatequina, Galocatequina-(2 $\rightarrow 0 \rightarrow 7,4 \rightarrow 8)-4-O$-metil-galocatequina, Galocatequina-3-O-galoil-2-O-7,4 $\rightarrow 8$ )4- $O$-metilgalocatequina, Miricetina- $O$ - $(O$-galoil $)$-hexosideo, Miricetina-3-O-galactosideo, Miricetina-galoilramnosideo, Quercetina-3- $O$-(2-galoil)-ramnososideo, Miricetina-3- $O$-acetil-ramnosideo, Miricetina-3- $O$-ramnose-3$O$-ramnosideo, (Epi)galocatequina-3-O-(3,5-O-dimetil)-galato, e 4-metil-(epi)galocatequina-3- $O$-)-galato, nenhuma destas substâncias atendeu as regras de Lipinski, apresentaram uma forte hidrofilicidade, que pode ocorrer devido altos graus de aceptores e baixo grau de doadores de hidrogênio, todos apresentam área de superfície polar maior que $140 \mathrm{~A}^{2}$ e baixo $\log \mathrm{P}$, isso ainda está correlacionado com a baixa absorção intestinal e baixa permeabilidade para células Caco2 e MDCK, que corroboram a sua baixa biodisponilidade oral. Os compostos apresentaram uma maior toxicidade em organismos mais complexos (peixes Medaka e Minnow), porém em organismos mais simples não apresentaram toxicidade (algas e Daphnia). Todas as substâncias possuem uma forte atividade antioxidante, são sequestradores de radicais livres, quimiopreventivos, anticarcinogênicos e antineoplásica, esta atividade pode estar correlacionada com a redução das espécies reativas de oxigênio, impedindo que estas causem danos ao DNA e consequentemente, a carcinogênese. As substâncias parecem ser promissoras para a atividade anticâncer, sendo necessários estudos para elucidar o mecanismo de ação destas substâncias.
\end{abstract}

Palavras-chave: Inga laurina; Compostos fenólicos; Atividade biológica.

\begin{abstract}
Inga laurina Willd, belongs to the Fabaceae family, popularly used against fungal infections, several flavonic compounds have already been isolated from all its parts, but there are few studies that evaluate the pharmacokinetic, toxicological properties and their biological activities of these, due to this, this This article aims to evaluate such properties of flavonic compounds isolated from Inga laurina leaves. ChemSketch software, PreADMET, PASS online and Mcule databases were used. The results showed that Gallocatechin-(4a-8)-4-O-methylgallocatechin, Gallocatechin$(2 \rightarrow 0 \rightarrow 7,4 \rightarrow 8)-4-O$-methyl-gallocatechin, Gallocatechin-3-O-galoyl-2-O-7,4(8)-4- $O$-methylgallocatechin, Myricetin$O$-( $O$-galoyl)-hexoside, Myricetin-3- $O$-galactoside, Myricetin-galoyl-rhamnoside, Quercetin-3-O-(2-galoyl)rhamnoside, Myricetin-3-O-acetyl-rhamnoside, Myricetin-3-O-rhamnose-3-O-rhamnoside, (Epi)gallocatechin-3-O(3,5-O-dimethyl)-gallate, and 4-methyl-(epi)gallocatechin-3-O-)-gallate, none of these substances follow the Lipinski rules, they showed strong hydrophilicity, which may occur due to high degrees of acceptors and low degrees of hydrogen donors, all of which have a polar surface area greater than $140 \mathrm{~A}^{2}$ and $\operatorname{low} \log \mathrm{P}$, this is still correlated with low intestinal absorption and low permeability for Caco2 and MDCK cells, which corroborate their low oral bioavailability. The compounds showed greater toxicity in more complex organisms (Medaka and Minnow fish), but in simpler organisms
\end{abstract}


they did not show toxicity (algae and Daphnia). All substances have strong antioxidant activity, are free radical scavengers, chemopreventive, anticarcinogenic and antineoplastic, this activity may be correlated with the reduction of reactive oxygen species, preventing them from causing DNA damage and, consequently, carcinogenesis. The substances seem to be promising for anticancer activity, and studies are needed to elucidate the mechanism of action of these substances.

Keywords: Inga laurina; Phenolic compounds; Biological activity.

\section{Resumen}

Inga laurina Willd, pertenece a la familia Fabaceae, popularmente utilizada contra infecciones fúngicas, de todas sus partes ya se han aislado varios compuestos flavónicos, pero existen pocos estudios que evalúen las propiedades farmacocinéticas, toxicológicas y sus actividades biológicas de estos, debido a esto, este artículo tiene como objetivo evaluar dichas propiedades de compuestos flavónicos aislados de hojas de Inga laurina. Se utilizaron el software ChemSketch, PreADMET, PASS online y bases de datos Mcule. Los resultados mostraron que Gallocatechin-(4 $\alpha-8)-$ 4- $O$-methylgalocatechin, Gallocatechin- $(2 \rightarrow 0 \rightarrow 7,4 \rightarrow 8)-4-O$-methyl-galocatechin, Gallocatechin-3-O-galoyl-2- $O$ 7,4(8)-4- $O$-metilgalocatequina, miricetina- $O$-( $O$-galoil)-hexósido, miricetina-3- $O$-galactósido, miricetina-galoilramnósido, quercetina-3-O-(2-galoil)-ramnósido, miricetina-3- $O$-acetil-ramnósido, miricetina-3- $O$-ramnosa-3- $O$ ramnósido, (epi)galocatequina-3-O-(3,5-O-dimetil)-galato, y 4-metil-(epi)galocatequina-3-O-)-galato, ninguna de estas sustancias cumplió con las reglas de Lipinski, mostraron una fuerte hidrofilicidad, que puede ocurrir debido a altos grados de aceptores y bajos grados de donantes de hidrógeno, todos de que tienen un área de superficie polar superior a $140 \mathrm{~A}^{2}$ y un $\log \mathrm{P}$ bajo, esto aún se correlaciona con una baja absorción intestinal y una baja permeabilidad para las células Caco2 y MDCK, lo que corrobora su baja biodisponibilidad oral. Los compuestos mostraron mayor toxicidad en organismos más complejos (peces Medaka y Minnow), pero en organismos más simples no mostraron toxicidad (algas y Daphnia). Todas las sustancias tienen fuerte actividad antioxidante, son captadoras de radicales libres, quimiopreventivas, anticancerígenas y antineoplásicas, esta actividad puede estar correlacionada con la reducción de especies reactivas de oxígeno, evitando que causen daño en el ADN y, en consecuencia, carcinogénesis. Las sustancias parecen ser prometedoras para la actividad anticancerígena y se necesitan estudios para dilucidar el mecanismo de acción de estas sustancias.

Palabras clave: Inga laurina; Compuestos fenólicos; Actividad biológica.

\section{Introdução}

O gênero Inga (família Fabaceae), possui cerca de 300 espécies que ocorrem em regiões neotropicais, dentre essas, 140 ocorrem no Brasil, sendo distribuída de um extremo ao outro da região litorânea nos estados do Acre, Pará, Amazonas, Bahia, Ceará, Goiás, Mato Grosso, Minas Gerais, principalmente em florestas de várzea (Lima, Santos \& Porta, 2018).

Popularmente, diversas espécies desse gênero já são utilizadas, principalmente por comunidades indígenas da Amazônia, dentre esses usos, as flores de Inga rubiginosa são utilizadas como descongestionante nasal, as folhas de I. myriocephala para o fortalecimento de cabelos (Vivot et al., 2001), as cascas de I. edulis são utilizadas como anti-inflamatório e antidiarreico, as sementes de I. brachystachya, contra flatulências (Silva, Souza, Rogez, Rees \& Larondelle, 2007) e as folhas de I. laurina para baques e infecções fúngicas (Martins, 2017).

A I. laurina Willd (sinonímia I. fagícola), conhecida popularmente como ingá mirim, ingá branco, ingá feijão, é distribuída geograficamente nas Américas Central e do Sul, é uma árvore de grande porte, podendo atingir $15 \mathrm{~m}$ de altura, presença de ramos cilíndricos, glabros ou purulentos, sua inflorescência é espiciforme e axilares, com flores sésseis, ela floresce entre os meses de setembro a novembro e fornece frutos entre dezembro e janeiro (Possette \& Rodrigues, 2010; Sousa, Bastos \& Gurgel, 2011).

No Brasil, a I. laurina é distribuída nos estados da região norte (Acre, Amazonas e Pará), nordeste (Bahia, Maranhão e Pernambuco), centro-oeste (Goiás, Mato Grosso e Mato Grosso do Sul), todos os estados da região sudeste e no Sul, apenas no Paraná, ocorrendo nos domínios fitogeográficos da Amazônia, Caatinga, Cerrado e Mata Atlântica (Garcia \& Bonadeu, 2020).

Analisando o óleo essencial das folhas I. laurina foram detectados, por cromatografia gasosa acoplada à espectrômetro de massa, os seguintes compostos: geraniol, hexadecanol, nonacosano, fitona, ácido palmítico, linalool, hexan-1-ol, metil salicilato (Furtado, 2014). De extratos de I. laurina foram isolados: ácido gálico, galocatequina, quercetina, miricetina, galato de etila, miricetina-3-O-ramnosídeo, miricetina-3'-O-ramnose-3-O-galactosídeo, 4'-O-metil-(epi) -galocatequina (Martins, 2017), 
ácido elágico (Vivot et. al, 2001), ácido ascórbico (Milton \& Jenness, 1987), galoil depsídeos, como a galoil tirosina, m-digaloil tirosina, m-trigaloil tirosina (Lokvam, Clausen, Grapovm, Coley \& Kursar, 2007).

A atividade antioxidante dos extratos e frações das folhas e cascas foi avaliada pelo método do DPPH (1,1-difenil-2picrilhidrazil), e os extratos etanólicos da casca (Concentração Efetiva para 50\% ( $\mathrm{CE}_{50}=4,4 \mu \mathrm{g} / \mathrm{mL}$ ), folha $\left(\mathrm{CE}_{50}=10,4 \mu \mathrm{g} / \mathrm{mL}\right)$ frações de acetato de etila folha $\left(\mathrm{CE}_{50}=5,5 \mu \mathrm{g} / \mathrm{mL}\right)$ e casca $\left(\mathrm{CE}_{50}=7,2 \mu \mathrm{g} / \mathrm{mL}\right)$, butanol casca $\left(\mathrm{CE}_{50}=3,7 \mu \mathrm{g} / \mathrm{mL}\right)$ e metanólica casca $\left(\mathrm{CE}_{50}=4,6 \mu \mathrm{g} / \mathrm{mL}\right)$, sendo que todas as frações e extratos possuem elevada atividade, pois possuem $\mathrm{CE}_{50}$ abaixo de 50 $\mu \mathrm{g} / \mathrm{mL}$ (Martins, 2017).

Em um estudo diferente, com galoil depsídeos e derivados, a atividade antioxidante foi avaliada através do método do radical DPPH e superóxido NBT (Cloreto de Azul Nitrotetrazólio), sendo que os Ácido 3-(4-(3,4,5-trihidroxibenzoiloxi)-fenil)2-aminopropanoico (Concentração Inibitória para 50\% ( $\left(\mathrm{CI}_{50}\right)$ : NBT= $0.55 \mu \mathrm{g} / \mathrm{mL}$ e DPPH=1.55 $\mu \mathrm{g} / \mathrm{mL}$ ), Ácido 3-(4-(4-hidroxi, 3-metoxibenzoiloxi)-fenil)-2-aminopropanoico ( $\mathrm{CI}_{50}: \mathrm{NBT}=0.76 \mu \mathrm{g} / \mathrm{mL}$ e DPPH= 2,64 $\mu \mathrm{g} / \mathrm{Ml}$, Ácido 3-(4-(4-hidroxi,3,5dimetoxibenzoiloxi)-fenil)-2-aminopropanoico $\quad\left(\mathrm{CI}_{50}: \mathrm{NBT}=1,56 \mu \mathrm{g} / \mathrm{mL} \quad\right.$ e $\left.\mathrm{DPPH}=3,48 \mu \mathrm{g} / \mathrm{mL}\right)$, Ácido 3-(4-(4hidroxibenzoiloxi)-fenil)-2-aminopropanoico $\left(\mathrm{CI}_{50}: \mathrm{NBT}=1,78 \mu \mathrm{g} / \mathrm{mL}\right.$ e $\left.\mathrm{DPPH}=2,31 \mu \mathrm{g} / \mathrm{mL}\right)$ e o Ácido 3-(4-(3,4dihidroxibenzoiloxi)-fenil)-2-aminopropanoico $\left(\mathrm{CI}_{50}: \mathrm{NBT}=0,63 \mu \mathrm{g} / \mathrm{mL}\right.$ e $\left.\mathrm{DPPH}=1,89 \mu \mathrm{g} / \mathrm{mL}\right)$, todos os compostos apresentarem elevada atividade antioxidante, tanto contra o superóxido NBT e o radical DPPH (Rao, Ramanjaneyulu, Rambabu \& Devi, 2011).

O extrato de etanólico de I. laurina mostrou-se ativo contra clone de Plasmodium falciparum resistente a cloroquina $\left(\mathrm{CI}_{50}=62 \mu \mathrm{g} / \mathrm{mL}\right.$ ), sendo considerado parcialmente ativo (Antoun et al., 2001), e avaliando o óleo essencial das cascas e folhas, foi identificado uma baixa atividade antimicrobiana contra Porphyromanas gingivalis (Concentração Inibitória Mínima (CIM): folhas $=400 \mu \mathrm{g} / \mathrm{mL}$ e casca $=400 \mu \mathrm{g} / \mathrm{mL}$ ), Prevotella nigrescens (CIM: folhas $=400 \mu \mathrm{g} / \mathrm{mL}$ e casca $=400 \mu \mathrm{g} / \mathrm{mL}$ ), Streptococcus mutans (CIM: folhas $=400 \mu \mathrm{g} / \mathrm{mL}$ e casca $=400 \mu \mathrm{g} / \mathrm{mL}$ ), Streptococcus sanguinis (CIM: folhas $=400 \mu \mathrm{g} / \mathrm{mL}$ e casca $=400$ $\mu \mathrm{g} / \mathrm{mL}$ ), Streptococcus salivarius (CIM: folhas $=200 \mu \mathrm{g} / \mathrm{mL}$ e casca $=200 \mu \mathrm{g} / \mathrm{mL}$ ), Streptococcus sobrinus (CIM: folhas $=400$ $\mu \mathrm{g} / \mathrm{mL}$ e casca $=400 \mu \mathrm{g} / \mathrm{mL}$ ) (Furtado et al., 2014).

Apesar de serem muitos os estudos com extratos, frações e já terem sido identificados e isoladas algumas substâncias da I. laurina, são poucos os estudos avaliando as propriedades farmacocinética, efeitos tóxicos e atividades biológicas dos compostos fenólicos já identificados, devido isso, o objetivo deste trabalho é descrever os resultados in silico das características farmacocinéticas, toxicológicas e as atividades biológicas de compostos fenólicos isolados de I. laurina.

\section{Metodologia}

Inicialmente, foi realizado um levantamento bibliográfico, nas bases de dados SCIELO, Google Schollar, Periódicos CAPES, estudos realizados com Inga laurina, tendo como foco os compostos já isolados. As moléculas selecionadas foram desenhadas no programa ChemSketch versão 12.00, 2010, para as predições toxicológicas e farmacocinéticas, utilizou-se o software PreADMET (versão. 2.0), para as previsões de atividades biológicas, o PASS- Online (Way2Drug.com @ 2011 - 2021 - Versão 2.0), e para estimar as características físico-químicas dos compostos, o Mcule property calculator.

Os cálculos físico-químicos (ADMETox) foram realizados através da comparação com substâncias, de acordo com a regra de Lipinski (conhecida como regra dos cinco) e de líder-similar, que estabelecem que uma molécula deve apresentar 4 características: a) Massa Molecular menor que 500; b) aceptores de ligação de hidrogênio menor ou igual a 10; c) doadores de ligação de hidrogênio menor ou igual a 5, d) $\log \mathrm{P}$ menor ou igual a 5; e outro aspecto importante a ser considerado é a área da superfície polar menor que 140 A² (Lipinski, 2004).

$\mathrm{Na}$ predição da farmacocinética, foram utilizados os seguintes critérios: permeabilidade em Caco2 (Human Colon Adenocarcinoma Cells) e MDCK (Madin Darby Canine Kidney) (Alta $>70 \mathrm{~nm} / \mathrm{sec}$, média $4-70 \mathrm{~nm} / \mathrm{sec}$ e baixa $<4 \mathrm{~nm} / \mathrm{sec}$ ) 
(Yazdanian, Glynn, Wright \& Hawi, 1998); permeabilidade cutânea (alta: <0,1, baixa: > 0,1); Absorção intestinal humana (baixa - 0-20\%; média 20-70\%, e elevada >70\%) (Yee, 1997); se atravessa a barreira hematoencefálica (livremente >2,0, moderada 2,0-0,1 e reduzida ou não atravessa <0,1) e se há ligação à proteínas plasmáticas (ligado fortemente $>90 \%$ e moderada a fraca $<90 \%$ ) (Ajay, Bermis \& Murkco, 1999). Para a predição de metabolismo, foram utilizados os seguintes critérios: se os compostos sofrem ou não metabolismo de fase 1.

Para a predição da mutagenicidade utilizou-se o Teste de Ames, que utiliza diferentes estirpes da bactéria Salmonella typhimurium (TA98, TA100 e TA1535), a variável a ser testada é a capacidade da substância provocar a reversão de mutações para o crescimento em meio isento de histidina. Foram consideradas mutagênicas as substâncias que apresentaram reversão da mutação em uma ou mais bactérias, não-mutagênicas quando não foi observada nenhuma reversão em nenhuma bactéria, e ambíguo ou falso positivo quando não houve reversão da mutação em nenhum clone da bactéria e mesmo assim o programa classificou como mutagênico, o resultado não foi considerado (Ames, Mccann \&Yamasaki, 1975).

A predição do potencial carcinogênico em ratos e camundongos, utilizou como critérios os dados obtidos a partir do Food And Drug Administration (FDA) e National Toxicology Program (NTP), e cruzados com o banco de dados do PREADMET, sendo classificados em carcinogênico (+) e não-carcinogênico (-). Para a avaliação de toxicidade em organismos marinhos, os critérios utilizados foram os seguintes: para toxicidade em algas (tóxicos $<1 \mathrm{mg} / \mathrm{mL}$ e não-tóxicos $>1 \mathrm{mg} / \mathrm{mL}$ ) (Costa, Olivi, Botta \& Espindola, 2008): para Daphnia sp (tóxico $<0,22 \mu \mathrm{g} / \mathrm{mL}$ e não-tóxicos $>0,22 \mu \mathrm{g} / \mathrm{mL}$ ) (Guilhermino, Diamantino, Silva \& Soares, 2000), para Medaka (muito tóxico < $1 \mathrm{mg} / \mathrm{L}$, tóxico entre 1-10 mg/L, prejudiciais entre 10-100 $\mathrm{mg} / \mathrm{L}$ e não tóxico > $100 \mathrm{mg} / \mathrm{L}$ ) (Zucker, 1985) e para Minnow (Muito tóxico < 1mg/L; Tóxico 1-10 mg/L; levemente tóxica 10100 mg/L; Não-Tóxica > 100mg/L) (Costa et al., 2008).

A atividade biológica foi avaliada através da similaridade entre substâncias biologicamente ativas, como fármacos e outros compostos tóxicos, tendo-se como critério avaliativo, a Pa (probabilidade de atividade) de 0,7, ou seja, 70\% (Filimonov et al., 1995).

\section{Resultados e Discussão}

Foram escolhidos os compostos fenólicos que tenham sido isolados da fração de acetato de etila das folhas de I. laurina.

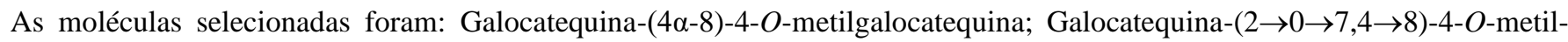
galocatequina; Galocatequina-3-O-galoil-2-O-7,4 $\rightarrow 8)-4-O$-metilgalocatequina; Miricetina- $O$-( $O$-galoil)-hexosideo; Miricetina3-O-galactosideo; Miricetina galoil ramnosideo; Quercetina-3- $O$-(2-galoil)-ramnososideo; Miricetina-3- $O$-acetil-ramnosideo; Miricetina-3-O-ramnose-3-O-ramnosideo; (Epi)galocatequina-3-O-(3,5-O-dimetil)-galato e 4-metil-(epi)galocatequina-3-O-)galato (Figura 1). As moléculas foram selecionadas partindo das informações encontradas em literatura acerca das moléculas mais abundantes encontradas na espécie em questão bem como seu potencial de atividade, partindo do pressuposto necessário e dos critérios estabelecidos anteriormente para que fosse possível a realização das avaliações propostas no referido trabalho. 
Figura 1. Compostos escolhidos para o estudo in silico.<smiles>COc1c(O)cc(C2Oc3c4c(O)cc(O)c3[C@H](c3ccc(O)cc3Oc3cc(O)c(O)c(O)c3)C(O2)C(O)C4O)cc1O</smiles>

1<smiles>O=C(OCC1OC(Oc2c(-c3cc(O)c(O)c(O)c3)oc3cc(O)cc(O)c3c2=O)C(O)C(O)C1O)c1cc(O)c(O)c(O)c1</smiles>

4<smiles>C[C@@H]1O[C@H](Oc2c(-c3ccc(O)c(O)c3)oc3cc(O)cc(O)c3c2=O)[C@H](OC(=O)c2cc(O)c(O)c(O)c2)[C@H](O)[C@H]1O</smiles><smiles>COc1cc(C(=O)OC2Cc3c(O)cc(O)cc3OC2c2cc(O)c(O)c(O)c2)cc(OC)c1O</smiles>

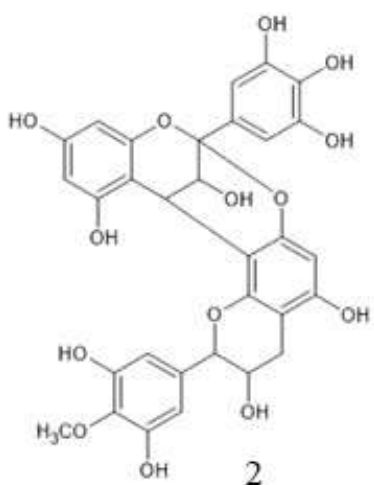

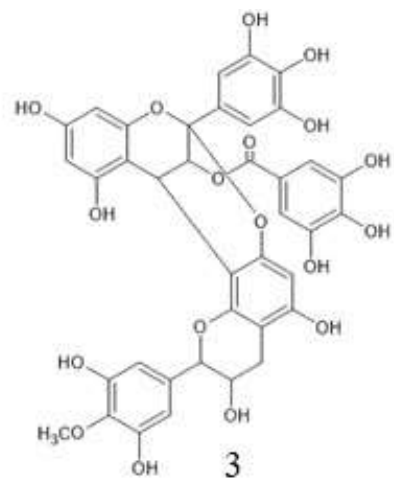<smiles>O=c1c(O[C@@H]2O[C@H](CO)[C@@H](O)[C@H](O)[C@H]2O)c(-c2cc(O)c(O)c(O)c2)oc2cc(O)cc(O)c12</smiles>

5<smiles>CC(=O)O[C@H]1C(Oc2c(-c3cc(O)c(O)c(O)c3)oc3cc(O)cc(O)c3c2=O)O[C@H](C)[C@@H](O)[C@H]1O</smiles>

8<smiles>COc1c(O)cc(C2Oc3cc(O)cc(O)c3CC2OC(=O)c2cc(O)c(O)c(O)c2)cc1O</smiles><smiles>C[C@@H]1O[C@H](OC2C(=O)c3c(O)cc(O)cc3OC2c2cc(O)c(O)c(O)c2)[C@H](OC(=O)c2cc(O)c(O)c(O)c2)[C@H](O)[C@H]1O</smiles>

6<smiles>C[C@@H]1OC(Oc2cc(C3Oc4cc(O)cc(O)c4CC3O[C@@H]3O[C@H](C)[C@@H](O)[C@H](O)[C@H]3O)cc(O)c2O)[C@H](O)[C@@H](O)[C@H]1O</smiles>

Legenda: 1- Galocatequina-(4 $\alpha-8)-4-O$-metilgalocatequina: 2 - Galocatequina-( $2 \rightarrow 0 \rightarrow 7,4 \rightarrow 8)-4-O$-metil-galocatequina; 3- Galocatequina-3$O$-galoil-2- $O-7,4 \rightarrow 8)$-4- $O$-metilgalocatequina; 4- Miricetina- $O$-( $O$-galoil)-hexosideo; 5- Miricetina-3- $O$-galactosideo; 6- Miricetina galoil ramnosideo; 7- Quercetina-3-O-(2-galoil)-ramnososideo; 8- Miricetina-3- $O$-acetil-ramnosideo; 9- Miricetina-3- $O$-ramnose-3- $O$-ramnosideo; 10- (Epi)galocatequina-3-O-(3,5-O-dimetil)-galato e 11- 4-metil-(epi)galocatequina-3-O-)-galato. Fonte: Autores.

Quanto aos critérios de Lipinski, apenas os compostos 5, 10 e 11 apresentaram massa molecular abaixo de 500, todos as outras possuem massa acima, sobre o $\log \mathrm{P}$, todos apresentaram valores menores que 5, se encaixando na regra, quanto a quantidade de aceptores de hidrogênio, todos apresentaram valores acima de 10, e quanto aos doadores de hidrogênio, as moléculas 1, 2, 5, 8 e 9 encaixam na regra, tendo valores menores ou iguais a 5, além disso, todos apresentaram valores de PSA (área superfície polar) maior que 140A² (Tabela 1) (Lipinski, 2004). 
Tabela 1 - Resultados das predições físico-químicas.

\begin{tabular}{lccccc}
\hline & Massa $(\mathrm{Da})$ & $\log \mathrm{P}$ & PSA & Aceptor de H+ & Doador de H+ \\
\hline 1 & 624.5435 & 2.7092 & 250.2200 & 14 & 4 \\
2 & 622.5276 & 2.5077 & 239.2200 & 14 & 3 \\
3 & 774.6313 & 3.4892 & 305.9800 & 18 & 6 \\
4 & 632.4780 & 0.1482 & 297.5000 & 13 & 7 \\
5 & 480.3743 & -0.8333 & 230.7400 & 16 & 4 \\
6 & 618.4946 & 0.7252 & 273.3600 & 15 & 6 \\
7 & 600.4792 & 1.4702 & 257.0400 & 13 & 5 \\
8 & 506.4115 & 0.7651 & 216.5800 & 15 & 5 \\
9 & 598.5484 & -1.3958 & 248.4500 & 11 & 6 \\
10 & 486.4233 & 2.8392 & 175.3700 & 11 & 6 \\
11 & 486.4233 & 2.8392 & 175.3700 & & 6 \\
\hline
\end{tabular}

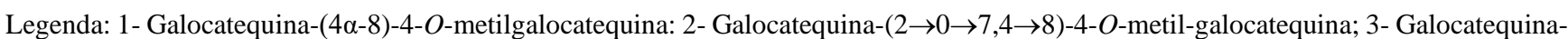
3- $O$-galoil-2- $O$-7,4 $\rightarrow 8)-4-O$-metilgalocatequina; 4- Miricetina- $O$ - $(O$-galoil)-hexosideo; 5- Miricetina-3- $O$-galactosideo; 6- Miricetina galoil ramnosideo; 7- Quercetina-3- $O$-(2-galoil)-ramnososideo; 8- Miricetina-3- $O$-acetil-ramnosideo; 9- Miricetina-3- $O$-ramnose-3- $O$ ramnosideo; 10- (Epi)galocatequina-3-O-(3,5-O-dimetil)-galato e 11-4-metil-(epi)galocatequina-3-O-)galato. PSA: Área da superfície polar. Da: Dalton. Fonte: Autores.

Nenhuma molécula se enquadrou na regra de Lipinski, porém isso não significa que se deve ignorar o potencial terapêutico destas moléculas, pois isso significa apenas que esses fármacos não possuem uma boa absorção via oral, pode-se fazer modificações químicas nessas substâncias para modificar os parâmetros que estão fora da regra da Lipinski, assim como, propor formas farmacêuticas projetadas específicas para essa substância, como nanoemulsões, cremes, pomadas, etc. (Lipinski, 2004).

Além disso, todos os compostos apresentaram um forte grau de aceptores e baixo grau de doadores de hidrogênio o que significa que todas as substâncias possuem uma forte tendência a formar ligações covalentes hidrogeniônicas (Rocha, 2015) favorecendo o desenvolvimento de um caráter mais hidrofílico as moléculas (Vilar, 2021). Ademais, quanto a superfície polar as moléculas também não atendem aos critérios de >140 A². Assim, uma vez que área de superfície polar topológica da molécula (TPSA), está relacionada à formação de ligação de hidrogênio, tal resultado corrobora a forte tendencia das moléculas em formar pontes de hidrogênio e suas características predominantemente hidrofílicas (Rodrigues, Avelino, Siqueira, Ramos \& Santos, 2021).

A avaliação desses resultados permite obter o nível de redução da flexibilidade molecular, que é medida pelo número de ligações rotativas, e a baixa área de superfície polar ou a contagem total de ligações de hidrogênio (soma de doadores e aceitadores) o que possibilita predizer se os compostos possuem boa biodisponibilidade oral, independente do peso molecular (Veber et al., 2002).

Todas as substâncias apresentaram um $\log$ P baixo (Tabela 1), logo todos os compostos possuem um caráter predominantemente hidrofílico. Esse caráter também é justificado pelo alto valor de doadores de hidrogênio, que se correlaciona com as dificuldades de absorção das moléculas (Tabela 2), na qual demonstra que todas as moléculas uma baixa ou moderada absorção cutânea e intestinal (Santos, Daniel, Próspero \& Costa., 2018). 
Tabela 2 - Predição dos aspectos farmacocinéticos dos compostos fenólicos escolhidos.

\begin{tabular}{|c|c|c|c|c|c|c|c|c|}
\hline \multirow{2}{*}{ Moléculas } & \multicolumn{4}{|c|}{ Absorção } & \multicolumn{2}{|c|}{ Distribuição } & \multirow{2}{*}{$\begin{array}{c}\text { Metabolismo } \\
\text { Fase } 1\end{array}$} & \multirow{2}{*}{$\begin{array}{c}\text { Inibição } \\
\text { CYP }\end{array}$} \\
\hline & Cutânea & MDCK & $\mathrm{Caco} 2$ & HIA & PP & BHE & & \\
\hline 1 & Baixa & Baixa & Média & Baixa & Alta & NA & CYP 3A4 & $\begin{array}{c}\text { CYP3A4, CYP2C9, } \\
\text { CYP2C19 }\end{array}$ \\
\hline 2 & Baixa & Baixa & Média & Baixa & Alta & NA & CYP 3A4 & $\begin{array}{c}\text { CYP3A4, CYP2C9, } \\
\text { CYP2C19 }\end{array}$ \\
\hline 3 & Baixa & Baixa & Média & Baixa & Alta & NA & CYP 3A4 & $\begin{array}{c}\text { CYP3A4, CYP2C9, } \\
\text { CYP2C19 }\end{array}$ \\
\hline 4 & Baixa & Baixa & Média & Baixa & Alta & NA & Fracamente & $\begin{array}{c}\text { CYP3A4, CYP2C9, } \\
\text { CYP2C19 }\end{array}$ \\
\hline 5 & Baixa & Baixa & Média & Baixa & Baixa & NA & Fracamente & $\begin{array}{c}\text { CYP3A4, CYP2C9, } \\
\text { CYP2C19 }\end{array}$ \\
\hline 6 & Baixa & Baixa & Média & Baixa & Alta & NA & Fracamente & $\begin{array}{c}\text { CYP3A4, CYP2C9, } \\
\text { CYP2C19 }\end{array}$ \\
\hline 7 & Baixa & Baixa & Média & Baixa & Alta & Moderamente & Fracamente & $\begin{array}{c}\text { CYP3A4, CYP2C9, } \\
\text { CYP2C19 }\end{array}$ \\
\hline 8 & Baixa & Baixa & Média & Baixa & Baixa & NA & Fracamente & $\begin{array}{c}\text { CYP3A4, CYP2C9, } \\
\text { CYP2C19 }\end{array}$ \\
\hline 9 & Baixa & Baixa & Média & Baixa & Baixa & NA & Fracamente & $\begin{array}{c}\text { CYP3A4, CYP2C9, } \\
\text { CYP2C19 }\end{array}$ \\
\hline 10 & Baixa & Baixa & Média & Média & Alta & Moderamente & Fracamente & $\begin{array}{c}\text { CYP3A4, CYP2C9, } \\
\text { CYP2C19 }\end{array}$ \\
\hline 11 & Baixa & Baixa & Média & Média & Alta & Moderamente & Fracamente & $\begin{array}{c}\text { CYP3A4, CYP2C9, } \\
\text { CYP2C19 }\end{array}$ \\
\hline
\end{tabular}

Legenda: 1 - Galocatequina-(4a-8)-4- $O$-metilgalocatequina: 2 - Galocatequina-(2 $\rightarrow 0 \rightarrow 7,4 \rightarrow 8)-4-O$-metil-galocatequina; 3- Galocatequina-3$O$-galoil-2- $O$-7,4 $\rightarrow 8)-4-O$-metilgalocatequina; 4- Miricetina- $O$-( $O$-galoil)-hexosideo; 5- Miricetina-3-O-galactosideo; 6- Miricetina galoil ramnosideo; 7- Quercetina-3-O-(2-galoil)-ramnososideo; 8- Miricetina-3- $O$-acetil-ramnosideo; 9- Miricetina-3- $O$-ramnose-3- $O$-ramnosideo; 10- (Epi)galocatequina-3- $O$-(3,5- $O$-dimetil)-galato e 11-4-metil-(epi)galocatequina-3- $O$-)galato. Permeabilidade cutânea (alta: $>0,1$, baixa: < 0,1); Caco-2 (Human Colon Adenocarcinoma Cells) e MDCK (Madin Darby Canine Kidney) (Alta $>70 \mathrm{~nm} / \mathrm{sec}$, média 4-70 nm/sec e baixa $<4 \mathrm{~nm} / \mathrm{sec}$ ); Absorção intestinal humana (HIA) (baixa - 0-20\%; média 20-70\%, e elevada >70\%); Ligação à proteínas plasmáticas (PP) ligado fortemente $>90 \%$ e moderada a fraca $<90 \%$ ); Atravessa a barreira hematoencefálica (BHE) (livremente >2,0, moderada 2,0-0,1 e reduzida ou não atravessa (NA) <0,1). Fonte: Autores, Yee, (1997); Ajay, Bermis \& Murkco, (1999); Yazdanian et al, (1998).

As substâncias 5, 10 e 11, apresentaram massa inferior a $500 \mathrm{Da}$, isso significa que apenas estas moléculas podem atravessar membranas celulares passivamente, isso se correlaciona com os dados nos estudos farmacocinéticos (Tabela 2). As moléculas 10 e 11, são as únicas que apresentam uma média absorção intestinal humana, a 5 possui uma baixa absorção, e isso está relacionado ao seu $\log \mathrm{P}$ negativo (-0.8333), que o torna muito hidrofílico, formando pontes de hidrogênio e consequentemente não é absorvido pelo intestino (Tabelas 1 e 2) (Santos et al., 2018; Waterbeemd \& Gifford, 2003).

A absorção cutânea em todas as substâncias foi considerada baixa (Tabela 2), sabe-se que, para um fármaco ser bem absorvido pela pele, ele deve possuir um caráter lipofílico, para poder ser difundido passivamente entre as camadas da pele, tendo isso em vista, observa-se que o $\log \mathrm{P}$ das substâncias é baixo (Tabela 1), logo possuem caráter hidrofílico, outros fatores como a grande massa molecular também interferem na absorção cutânea dessas moléculas (Alves, 2015). 
Células Madin Darby Canine Kidney (MDCK), são utilizadas para como modelo de estudo para a avaliação da permeabilidade de membranas (Dezani, 2017). No presente estudo, todas as substâncias possuem baixa absorção para estas células (Tabela 2). Assim, pode-se inferir que as moléculas em questão possuem um índice de permeabilidade baixo corroborando o demonstrado por suas predições expostas (Tabela 1). Além disso, considera-se que moléculas com baixa absorção pelas células MDCK estão mais propensas a possuírem uma grande massa molecular, bem como são mais capazes de formar ligações externas de hidrogênio dificultando sua absorção epitelial (Chen et al, 2018).

As células epiteliais de carcinoma do cólon humano (Caco2) são um dos modelos de estudo utilizados para a predição de absorção intestinal in vitro, tais células são capazes de formar uma monocamada celular polarizada, produzindo uma similaridade funcional e morfológica referentes as células do intestino delgado, enzimas e diferentes tipos de transportadores. Assim, sua utilização possibilita uma avaliação acerca da permeabilidade de compostos principalmente no que diz respeito a substâncias transportadas passivamente (Chen et al, 2018; Dezani, 2017). Diferente ao observado para as células MDCK, todas as substâncias analisadas possuem uma média absorção (Tabela 2). Significando que para as células Caco2 as moléculas em questão possuem um melhor nível de permeabilidade, ou seja, estão mais propensas a transpassar membranas. Isso pode estar relacionado ao fato de as moléculas possuírem um caráter predominantemente hidrofílico o que as torna altamente polarizadas facilitando que elas se difundam pela monocamada celular que também é altamente polarizada (Mochiutti, Carvalho, Nascimento, Brasil \& Martelli, 2019).

A maneira como substâncias atravessam uma monocamada de células Caco2 e de MDCK é semelhante à absorção da mucosa intestinal, por isso há uma grande correlação das Células MDCK e Caco2 com esta propriedade, mesmo que ambas linhagens são provenientes de diferentes organismos (Humanos para a Caco-2 e Cães para MDCK), e certos transportadores estarem em maior ou menor quantidade, e estas diferenças celulares podem explicar os resultados diferentes obtidos no presente estudo (Balimane \& Chong, 2005; Irvine et al., 1998).

A predição da absorção intestinal humanal apontou que apenas as substâncias 10 e 11 possuem média absorção e as demais, uma baixa absorção (Tabela 2). Quando se relaciona estes resultados aos obtidos com as células MDCK, esperava-se que todos os compostos apresentassem uma baixa absorção intestinal. No entanto, ao se relacionar aos resultados obtidos nas células Caco2, a expectativa foi de média absorção e tal fato se confirmou apenas para os compostos 10 e 11 (Tabela 2). A baixa absorção intestinal das moléculas pode estar relacionada a fatores físico-químicos, como o LogP e massa molecular (Santos, Daniel, Próspero \& Costa, 2018). No presente estudo observa-se que as moléculas 10 e 11 possuem massa molecular inferior a 500 Dalton e LogP superior a 2,0, provavelmente, estes fatores podem contribuis para uma melhor absorção intestinal (Tabela $1)$.

No referente à distribuição das substâncias estudadas, as substâncias 5, 8 e 9 são as únicas que possuem baixa ligação a proteínas plasmáticas (PP) e todas as outras se ligam fortemente (Tabela 2). Características químicas das moléculas podem interferir na ligação as proteínas e sabe-se que substâncias de caráter ácido possuem afinidade albumina, enquanto que compostos básicos podem se ligar a glicoproteína ácida $\alpha$ (Horta, 2018). A ligação de forma elevada a albumina de um composto deve ser considerada durante a sua associação com outros fármacos que também ligam de forma elevada a esta proteína, pois pode ocorrer competição pelo sítio de ligação, sendo alterado o equilíbrio entre a fração livre e ligada de um dos compostos (Vasconcelos, 2019). O composto com maior fração livre pode ser mais amplamente distribuído, podendo ocorrer elevação do risco de eventos adversos (Silva, 2021).

Outra questão importante avaliada foi a predição das moléculas atravessarem a barreira hematoencefálica (BHE), atingindo o Sistema Nervoso Central (SNC). As substâncias 7, 10 e 11, os resultados sugerem que atravessam moderadamente, as demais não atravessam ou atravessam de maneira bem reduzida (Tabela 2). Tais resultados já eram esperados, pois substâncias 
com grande massa molecular superior a $500 \mathrm{D}$ não conseguem atravessar. Também, o baixo caráter apolar (logP reduzido) pode explicar tal fato (Tabela 1), pois apenas compostos lipofílicos conseguem se distribuir amplamente para o SNC (Bentes, 2016).

No que concerne à predição do metabolismo das moléculas, as substâncias 1, 2 e 3 são metabolizados pela CYP3A4 (Tabela 2). Algumas características químicas das moléculas são importantes, pois o metabolismo de fase 1 tem como objetivo tornar as moléculas mais polares, facilitando a sua eliminação (Martins, 2019). No presente estudos, moléculas com maiores $\log \mathrm{P}, \log$ mais lipofílicas, parecem ser metabolizadas por enzima envolvida no metabolismo de fase 1 (Tabela1).

A inibição ou indução de uma CYP, possui uma forte relação com suas propriedades físico químicas, como o $\log$, massa molecular, número de aceptores de hidrogênio. No estudo em questão, todas as moléculas inibiram as CYPs, 3A4, 2C9, 2C19 (Tabela 2). A grande quantidade de aceptores de hidrogênio, talvez, é a responsável por essa inibição (Tabelas 1 e 2), devido a formação de possíveis pontes de hidrogênio com o sítio alostérico da CYP (Ferreira, 2017). Substancias que inibem CYPs 3A4, 2C9 e 2C19 podem interferir no metabolismo de outros fármacos, podem alterar as concentrações plasmáticas destes, elevando o risco de eventos adversos (Silva, 2015). Ao se associar um fármaco que é metabolizado por uma CYP, ao inibidor desta, pode-se fazer ajuste na dose do fármaco, reduzindo o risco de toxicidade (Braz, 2018).

Além da predição dos aspectos físico-químicos e farmacocinéticos, é importante avaliar o potencial toxico das substâncias, podendo ser utilizado diferentes modelos experimentais. No presente estudo foi avaliado o potencial tóxico em Algas, não sendo observada toxicidade das substâncias para estas (Tabela 3). Este resultado sugere que, provavelmente, estes compostos não apresentam toxicidade aguda, entretanto, é importante confirmar esta informação utilizando modelos adicionais como o ensaio de toxicidade oral aguda em roedores (Costa et al., 2008).

Tabela 3 - Predição dos aspectos toxicológicos dos compostos fenólicos escolhidos.

\begin{tabular}{llccccccccccc}
\hline & & 1 & 2 & 3 & 4 & 5 & 6 & 7 & 8 & 9 & 10 & 11 \\
\hline \multirow{4}{*}{ Toxicidade } & Algae & - & - & - & - & - & - & - & - & - & - & - \\
& Daphnia & - & - & - & - & + & + & - & + & + & - & - \\
& Minnow & ++ & ++ & ++ & ++ & + & ++ & ++ & ++ & ++ & ++ & ++ \\
\multirow{3}{*}{ Mutagenicidade } & Medaka & ++ & ++ & ++ & ++ & ++ & ++ & ++ & ++ & ++ & ++ & ++ \\
\multirow{2}{*}{ Carcinogenicidade } & Teste de Ames & NM & NM & NM & NM & NM & NM & NM & NM & NM & NM & NM \\
& Ratos & C & C & C & NC & NC & NC & C & NC & NC & C & C \\
& Camundongos & NC & NC & NC & C & NC & NC & C & NC & NC & NC & NC \\
\hline
\end{tabular}

Legenda: 1- Galocatequina-(4a-8)-4- $O$-metilgalocatequina: 2 - Galocatequina- $(2 \rightarrow 0 \rightarrow 7,4 \rightarrow 8)-4-O$-metil-galocatequina; 3- Galocatequina3-O-galoil-2-O-7,4 $\rightarrow 8)$-4- $O$-metilgalocatequina; 4- Miricetina- $O$-( $O$-galoil)-hexosideo; 5- Miricetina-3- $O$-galactosideo; 6- Miricetina galoil ramnosideo; 7- Quercetina-3- $O$-(2-galoil)-ramnososideo; 8- Miricetina-3- $O$-acetil-ramnosideo; 9- Miricetina-3- $O$-ramnose-3- $O$ ramnosideo; 10- (Epi)galocatequina-3-O-(3,5-O-dimetil)-galato e 11- 4-metil-(epi)galocatequina-3-O-)galato. Toxicidade em algas: ++: Muito tóxico; + Tóxico; +-: Moderadamente tóxico; -: Não Tóxico; Carcinogenicidade: C: Carcinogênico; NC: Não carcinogênico e Mutagenicidade: M: Mutagênico; NM: Não Mutagênico. Fonte: Autores, Costa et al., (2008), Zucker, (1985), Guilhermino, Diamantino, Silva \& Soares, (2000).

Diferente do observado no ensaio em Algas, os compostos 5, 6, 8 e 9 parecem ser tóxicos para o crustáceo Daphnia (Tabela 3). Este modelo pode predizer a toxicidade aguda de um composto, bem como os eventos tóxicos relacionados a administração de múltiplas doses (toxicidade sincrônica) (Costa et al., 2008). A alta massa molecular, junto da área de superfície polar e os aceptores e doadores de hidrogênio (Tabela 1), demonstram a alta hidrofilicidade desses compostos, o que os torna bem fáceis de se dissolverem nos leitos d'agua e consequentemente, nas algas uni e pluricelulares, porém, isso significa que esses compostos são excretados facilmente, o que pode ser a justificativa para não haver toxicidade nesses (Waterbeemd \& Gifford, 2003). 
Na predição da toxicidade em peixes (Medaka e Minnow), todos os compostos se mostraram muito tóxicos (Tabela 3). Os modelos que utilizam peixes podem sinalizar os efeitos da intoxicação aguda e crônica frente as substâncias testes, é importante ressaltar que as diferenças de toxicidades entre diferentes organismos são esperadas, pois os organismos são fisiologicamente diferentes, além de pertencer a diferentes níveis tróficos. Entretanto, espera-se que substâncias sejam mais tóxicas nos primeiros níveis tróficos, pois são organismos menos complexos e qualquer leve alteração pode levar a mudanças drásticas na ecologia desta população. Contraditoriamente, as substâncias se mostraram mais tóxicas nos organismos mais complexos, os peixes, possivelmente isso deve ocorrer pela dupla exposição às substâncias, o contato branquial direto e a ingestão de algas contaminadas, além de que, devido serem organismos de maior complexidade, esses xenobiótico podem causar alterações tissulares graves (Costa et al., 2008; Martins, 2015).

Outra questão muito importante avaliada foi o potencial mutagênico dos compostos, cujos resultados sugerem não ser mutagênicos para os isolados de Salmonella typhimurium utilizados nesta predição (Tabela 3). Compostos fenólicos possuem a capacidade de sequestrar radicais livres, sendo que estes são as principais causas de danos ao DNA, devido isso, espera-se que estes não sejam genotóxicos, e sim genoprotetores, essa característica destes compostos já é bem descrita na literatura (Sá et al., 2012; Verruck, Prudêncio \& Silveira, 2018).

Acerca da predição de carcinogenicidade em ratos, as substâncias 1, 2, 3, 7, 10 e 11, foram caracterizadas como carcinogênica, já em camundongos, apenas as substâncias 4 e 7 são carcinogênicas. Apenas a substância 7 mostrou-se carcinogênica em para camundongos e ratos (Tabela 3) e, por isso, merece uma maior atenção. Contrariando a literatura, alguns compostos estudados se apresentaram como carcinogênicos, tendo em vista que, compostos flavônicos auxiliam no sequestro de radicais livres, e apresentam uma conhecida atividade antiproliferativa contra diversas linhagens tumorais, além disso, estudos epidemiológicos apontam que dietas ricas em compostos flavônicos diminuem a incidência de câncer em humanos, estudos utilizando modelos animais com os compostos isolados são necessários para entender a carcinogenicidade apresentada (Dornas, Oliveira, Dores, Santos \& Nagem, 2007; Lee, Lee, Surh \& Lee, 2003)

Outro ponto importante deste estudo foi a predição de atividades biológicas, sendo que, exceto o composto 2 , todas as substâncias parecem ser promissoras como antitumorais (Tabela 4). Proantocianidinas como as substâncias 1, 2, 3, 10 e 11 são conhecidamente antitumorais, em um estudo utilizando proantocianidinas de cacau e sintéticas (idênticas à natural), estas foram capazes de inibir células tumorais (linhagens MCF-7, MDA-MB-453 e SKBR-BR), sendo ainda possível estabelecer que esta inibição ocorre através da paralisação do ciclo celular, levando a morte celular por necrose e não por apoptose (Kozikowski, Tuckmantel, Bottcher \& Romanczyk, 2003). Já a Miricetina-3-O-galactosideo inibiu as células de leucemia crônica humana nas concentrações de 50 (Taxa de Inibição (TI): 21\%), 100 (TI: 41\%), 200 (TI: 48\%), 400 (TI:57\%) e 800 (62\%), possuindo moderada atividade contra esta linhagem (Hayder et al., 2008). A Quercetina-3-O-Ramnosídeo apresentou forte citotoxicidade $\left(\mathrm{CC}_{50}: 46,67 \mu \mathrm{g} / \mathrm{mL}\right)$ contra células de câncer cervical (HeLa) (Herni, Subarnas, Diantini \& Iskandar, 2021). 
Tabela 4 - Predição de atividades biológicas dos compostos escolhidos

\begin{tabular}{|c|c|c|c|c|c|c|c|c|c|c|c|}
\hline & 1 & 2 & 3 & 4 & 5 & 6 & 7 & 8 & 9 & 10 & 11 \\
\hline \multicolumn{12}{|c|}{ Câncer } \\
\hline Antineoplásica & + & - & + & + & + & + & + & + & + & + & + \\
\hline Estimulante da Caspase 3 & - & - & - & - & - & + & - & - & + & - & - \\
\hline Estimulante da Caspase 8 & - & - & - & - & - & - & - & - & - & - & - \\
\hline Anticarcinogênica & + & + & + & + & + & + & + & + & + & + & + \\
\hline Antimutagênica & + & + & + & + & + & - & + & + & + & - & + \\
\hline Quimiopreventivas & + & + & + & + & + & + & + & + & + & + & + \\
\hline Antioxidante & + & + & - & + & + & + & + & + & + & + & + \\
\hline Sequestrador de Radicais Livres & + & + & + & + & + & + & + & + & + & + & + \\
\hline \multicolumn{12}{|c|}{ Microrganismos e Parasitas } \\
\hline Antifúngica & - & - & - & + & + & + & + & + & + & - & - \\
\hline Antimicrobiana & - & - & - & - & - & - & - & + & - & - & - \\
\hline Antiviral & - & - & - & - & - & - & - & - & - & - & - \\
\hline Antiprotozoária & - & - & - & - & - & - & - & - & - & - & - \\
\hline \multicolumn{12}{|c|}{ Resposta Inflamatória } \\
\hline Anti-inflamatória & - & - & - & + & + & - & + & + & - & - & - \\
\hline Antieczema & - & - & - & - & - & - & - & - & - & + & + \\
\hline
\end{tabular}

Legenda: $\quad 1-\quad$ Galocatequina-(4a-8)-4- $O$-metilgalocatequina: $\quad 2-\quad$ Galocatequina- $(2 \rightarrow 0 \rightarrow 7,4 \rightarrow 8)-4-O$-metil-galocatequina; $\quad 3-$ Galocatequina-3- $O$-galoil-2- $O$-7,4 $\rightarrow 8$ )-4- $O$-metilgalocatequina; 4- Miricetina- $O$-( $O$-galoil)-hexosideo; 5- Miricetina-3- $O$-galactosideo; 6- Miricetina galoil ramnosideo; 7- Quercetina-3-O-(2-galoil)-ramnososideo; 8- Miricetina-3-O-acetil-ramnosideo; 9- Miricetina-3- $O$ ramnose-3- $O$-ramnosideo; 10- (Epi)galocatequina-3-O-(3,5-O-dimetil)-galato e 11- 4-metil-(epi)galocatequina-3- $O$-)galato. $\quad+$ : Probabilidade de atividade $>0,7,-$ :Probabilidade de atividade<0,7. Fonte: Autores, Filimonov et al., (1995).

Visando compreender o mecanismo envolvido nesta atividade antitumoral foi avaliado a atividade de todos os compostos frente as caspases 3 e 8. Somente as substâncias 6 e 9 apresentaram a capacidade de estimular a caspase 3 (Tabela 4 ), esses dados encontrados corroboram com a literatura, pois estudos indicam que a atividade citotóxica de proantocianidinas frente à linhagem MCF-7, é realizada pelo sistema apoptótico Fas/FasL, sem ativação de p53 e p21/WAFI, isso demonstra que estas substâncias não conseguem estimular diretamente as caspases, sendo necessário ativar os sistemas pró-apoptose para poder causar sua citotoxicidade (Kuo, Hsu, Lin \& Lin, 2005).

Nas predições de quimioprofilaxia e anticarcinogênica sugerem que todas as substâncias possuem este potencial, e somente a 3 parece não apresentar atividade antimutagênica. Estas atividades podem estar relacionadas ao potencial antioxidante e no sequestro de radicais livres (Tabela 4). Sabe-se que compostos fenólicos possuem grande potencial antioxidante devido sua capacidade de sequestrar radicais livres, estes compostos podem tanto retardar ou inibir a oxidação de lipídios ou outras substâncias, evitando assim, a formação de radicais livres (Verruck, Prudêncio \& Silveira, 2018).

Um estudo utilizando a epigalocatequina- $(2 \mathrm{a} \rightarrow 7,4 \alpha \rightarrow 8)$-epicatequina, que possui estrutura semelhante à molécula 2 deste estudo, apresentou moderada atividade antioxidante, utilizando o método de auto oxidação do $\beta$-caroteno (Valor de atividade: 35) (Barreiros, David, Queiroz \& David, 2000), além disso, a Quercetina-3-O-ramnosideo, apresenta uma alta atividade antioxidante através do método DPPH, com $\mathrm{CC}_{50}$ igual a 0,0009 mM (Zhang et al. 2017), esses achados demonstram que mesmo isolados as substâncias estudadas permanecem efetivas e em baixas concentrações. Certos flavonóides (epigalocatequina, epicatequina e epigalocatequina) podem agir como tratamento quimioterápico adjuvante, pois sua ação moduladora do ciclo celular contribui para potencializar os efeitos de quimioterápicos, porém esse processo precisa ser melhor estudado (Farabegoli, Barbi, Lambertini \& Piva, 2007). 
Compostos fenólicos agem utilizando o mecanismo detoxificador para sequestrar radicais livres, esse é constituído pela glutationa reduzida, superóxido-dismutase, catalase, glutationa-redutase e vitamina E, estas enzimas tem como principal função a redução de espécies reativas de oxigênio (ROS), isso torna-as mais estáveis, portanto, menos reativas, como consequência deste processo, essas substâncias não correm o risco de reagir com componentes celulares importantes, como as bases nitrogenadas presentes no DNA. O mecanismo anterior é provavelmente o utilizado pelas moléculas analisadas nesse estudo (Tabela 4; Verruck, Prudêncio \& Silveira, 2018).

Uma substância ser considerada anticarcinogênica, significa que ela pode reverter ou impedir o processo de carcinogênese de uma célula normal, e para uma molécula ser considerada antimutagênica, ela deve poder impedir danos ao DNA ou conseguir reverter ou estimular a reversão de danos já causados. Nesse contexto, as moléculas estudadas provavelmente agem impedindo tanto o processo de carcinogênese quanto de mutagênese ao sequestrar e impedir a ação dos radicais livres nas células normais (Guerra, 2016, Lopes, Oliveira \& Prado, 2002; Verruck, Prudêncio \& Silveira, 2018).

Na predição das predições de atividade antifúngica, as substâncias 4, 5, 6, 7, 8 e 9 parecem ser promissoras (Tabela 4). Estudo anterior demonstrou a quercetina não apresentou potencial antifúngico frente às linhagens padrão de C. albicans ATCC 40227 e C. krusei ATCC 6538. No entanto, Quercetina-3-O-(2-galoil)-ramnosideo parece ser promissor (Tabela 4), tornando-se necessário estudos adicionais. Além disso, a Miricetina-3-O-ramnosideo, apresentou atividade contra C. albicans, C. tropicalis e C. glabrata tendo $\mathrm{CC}_{50}$ de até $89,5 \mu \mathrm{g} \mathrm{mL}$ (Martins et al., 2020).

Para os demais microrganismos (bactérias, vírus e protozoários), as substâncias selecionadas não parecem ser promissoras. No entanto, outros estudos demonstraram que quercetina e derivados, apresentaram atividade antipoliovírus, apesar de não ser virucida (Vrijsen, Everaert, \& Boeyé, 1988), e catequinas e epicatequina foram ativas frente à adenovírus, EpsteinBarr e Herpes simplex vírus (Friedman, 2007).

Em geral, a atividade antibacteriana de flavonoides não é muito comum (Verruck, Prudêncio \& Silveira, 2018), este estudo reafirmou este fato e apenas 8 parece ser ativa (Tabela 4). A literatura relatou que miricetina e seus derivados, não apresentam atividades antimicrobiana quando isoladas (Rabelo, 2018). A Proantocianidina B3 que é um isômero da Galocatequina-(4a-8)-4-O-metilgalocatequina, não apresentou atividade contra Staphylococcus aureus, Bacillus subtilis, Escherichia coli e Pseudomonas aeruginosa (Ushirobira, 2003). Contrariando a predição biológica, o extrato de Rhus tripartita, que apresenta $78 \%$ de Miricetina-3-O-Galactosideo, sendo este seu composto majoritário, apresentou uma moderada atividade contra S. aureus (CC50: $125 \mu \mathrm{g} / \mathrm{mL}$ ), S. epidermidis (CC50: $250 \mu \mathrm{g} / \mathrm{mL}$ ), L. monocytogenes (CC50: $500 \mu \mathrm{g} / \mathrm{mL}$ ), acredita-se que por ser o composto majoritário, a Miricetina-3-O-Galactosideo, deva ser a responsável pela atividade bactericida, porém estudos com a substância isolada são necessários para comprovar isso (Tlili et al., 2019).

Inicialmente, esperava-se que algumas moléculas apresentassem atividade antiparasitária, entretanto, isso não ocorreu (Tabela 4). Estudo anterior demonstrou que a quercetina possui atividade imunomoduladora, sendo capaz de induzir apoptose em Trypanosoma brucei gambiense (Matsuda et al., 2004).

A respeito das suas atividades relacionadas à resposta inflamatória, as substâncias 4, 5, 7 e 8 apresentaram atividade anti-inflamatória, as 10 e 11, possuem atividade antieczema (Tabela 4), sabe-se que a quercetina possui ação anti-inflamatória por causar inibição da ciclo-oxigenase (COX2) e da sintase do óxido nítrico (ONS) (Mutoh et al., 2000; Raso, Meli, Carlo, Pacilio \& Carlo, 2001). Além disso, a miricetina é um conhecido anti-inflamatório através da inibição de citocinas inflamatórias (Kuo, 2005), e a Miricetina-3-O-Galactosídeo reduz o edema local nas concentrações de 0.26 e $0,78 \mathrm{mg} / \mathrm{kg}$, além de diminuir o tempo de lambida pelo teste da formalina, demonstrando seu potencial anti-inflamatório e antinociceptivo dessa (Azevedo et al., 2015). 


\section{Conclusão}

Nenhuma molécula avaliada seguiu a regra de Lipinski, sendo que a massa molecular elevada e baixo LogP impactaram nos aspectos farmacocinéticos, como absorção e distribuição, o que torna a absorção oral dessas moléculas mais dificultosa, sendo necessários estudos com outras possíveis formulações e tecnologias. Um fato importante e que deve ser levado em consideração é o elevado potencial inibitório de diferentes CYP pelos compostos, podendo ocorrer interação com diferentes fármacos, podendo ser necessário o ajuste de doses.

Alguns pontos importantes foram relatados neste estudo, estas moléculas parecem não ser mutagênicas, apresentando potencial anticarcinogênico, antimutagênico e quimiopreventivo. Provavelmente, estas atividades estão relacionadas a atividade antioxidante e capacidade de sequestrar radicais livres, porém são necessários estudos mais direcionados, como os de docking molecular.

Baseado nestes resultados, pode-se sugerir que é muito importante investigar a atividade anticâncer e antifúngica destes compostos, principalmente utilizando modelos in vitro, com linhagens de células neoplásicas e cepas de fungos, pois parecem ser muito promissores e o mecanismo de ação ainda não está claro. Também, investigar a atividade anti-inflamatória é importante, bem como o mecanismo de ação envolvido.

\section{Referências}

Ajay, A., Bermis, G.W. \& Murkco, M.A. (1999). Designing libraries with CNS activity. J Med Chem, 42, $4942-4951$.

Alves, N. C. (2015). Penetração de ativos na pele: revisão bibliográfica. Amazônia: science \& health, 3(4), 36-43.

Ames, B. N., Mccann, J. \& Yamasaki, E. (1975). Methods for detecting carcinogens and mutagens with the Salmonella/Mammalian-microsome mutagenicity test. Mutation Research(31), 347-364.

Antoun, M. D., Ramos, Z., Vazques, J., Oquendo, I., Proctor, G. R., Gerena, L. \& Franzblau. S. G. (2001). Evaluation of the Flora of Puerto Rico for in vitro Antiplasmodial and Antimycobacterial Activities. Phytotherapy Research, 15, 638-642.

Azevedo, A. de O., Campos, J. J., de Souza, G. G., de Carvalho Veloso, C., Duarte, I. D. G., Braga, F. C., \& Perez, A. de C. (2015). Antinociceptive and antiinflammatory effects of myricetin 3-O- $\beta$-galactoside isolated from Davilla elliptica: involvement of the nitrergic system. Journal of natural medicines, 69(4), 487-493.

Balimane, P. V. \& Chong, S. (2005). Cell culture-based models for intestinal permeability: a critique. Drug Discovery Today, 10 (5), $335-343$.

Barreiros, A. L B.S. de, David, J. M, David, J. P. \& Queiroz, L. P. (200). New proantocianidine of type A2 and flavonoids from leaves of Dioclea lasiophylla; Nova proantocianidina do tipo A2 e flavonoides das folhas de Dioclea lasiophylla. Brasil.

Braz, C. D. L., Figueiredo, T. P. D., Barroso, S. C. C., \& Reis, A. M. M. (2018). Medicamentos com atividade sobre o citocromo P450 utilizados por idosos em domicílio. Rev Med Minas Gerais, 28, 1-9.

Bentes, H. M. M. (2016). Desenho De Fármacos Assistido Por Computador: Aplicação À Permeação Através Da Barreira Hematoencefálica. Dissertação de Mestrado, Coimbra, Portugal. Disponível em: http://hdl.handle.net/10316/48311.

Chen, E. C., Broccatelli, F., Plise, E., Chen, B., Liu, L., Cheong, J., Zhang, S., Jorski, J., Gaffney, K., Umemoto, K. K. \& Salphati. (2018). Evaluating the Utility of Canine Mdr1 Knockout Madin-Darby Canine Kidney I Cells in Permeability Screening and Efflux Substrate Determination. Mol Pharm, 5 (11), $5103-5113$.

Costa, C. R., Olivi, P., Botta, C. M. R. \& Espindola, E. L. G. (2008). A toxicidade em ambientes aquáticos: discussão e métodos de avaliação. Quim Nova. 3(7), $1820-1830$.

Dezani, A. B. (2017). Avaliação dos mecanismos envolvidos na permeabilidade de fármacos antirretrovirais por meio dos modelos ex vivo (células de Franz) $e$ in vitro (PAMPA). Tese de Doutorado, Universidade de São Paulo, São Paulo, São Paulo, Brasil. https://www.teses.usp.br/teses/disponiveis/9/9139/tde24042017-144959/en.php

Dornas, W. C., Oliveira, T. T., Rodrigues-Das-Dores, R. G., Santos, A. F., Nagem, T. J. (2007). Flavonóides:potencial terapêutico no estress oxidativo. Revista de Ciências Farmacêuticas Básica e Aplicada, 28 (3), 241-249.

Farabegoli, F., Barbi, C., Lambertini, E., \& Piva, R. (2007). (-)-Epigallocatechin-3-gallate downregulates estrogen receptor alpha function in MCF-7 breast carcinoma cells. Cancer detection and prevention, 31(6), 499-504.

Ferreira, E. P. dos R. (2017). Planejamento e avaliação in sílica de análogos de lapachol em enzima alvo de Leishmania (Leishmania) amazonensis. Dissertação de Mestrado em Ciências Farmacêuticas. Universidade Federal do Pará, Belém, Pará, Brasil. http://repositorio.ufpa.br:8080/jspui/handle/2011/10728. 
Filimonov, D. A., Poroikov, V. V., Karaicheva, E. I., Kazarian, R. K., Budunova, A. P. \& Mikhailovskii, E. M. (1995). The Computerized Prediction of the spectrum of Biological Activity of Chemical Compounds by their structural formula: the PASS system: Prediction of activity Spectra for substance. Eksp Klin Farmakol; 58 (2), 56-62.

Friedman, M. (2007). Overview of antibacterial, antitoxin, antiviral, and antifungal activities of tea flavonoids and teas. Molecular nutrition \& food research, 51(1), 116-134.

Furtado, F. B. (2014). Estudo químico, análise do óleo essencial e atividades biológicas de Inga laurina (Sw.) Willd. Dissertação de Mestrado, Universidade de Uberlândia, Uberlândia, Uberlândia, São Paulo, Brasil. https://repositorio.ufu.br/handle/123456789/17408.

Furtado, F. F., Aquino, F. J. T., Nascimento, E. A., Martins, C. M., Morais. S. A. L, Chang, R., Cunha, L. C. S, Leandro, Martins, C. H. G. Martins, M. M, Silva, C. V. \& Machado, F. C. (2014). Oliveira, A. Seasonal Variation of the Chemical Composition and Antimicrobial and Cytotoxic Activities of the Essential Oils from Inga laurina (Sw.) Willd. Molecules, 19, 4560-4577.

Garcia, F.C.P. \& Bonadeu, F. (2020). Inga in Flora do Brasil. Jardim Botânico do Rio de Janeiro. http://floradobrasil.jbrj.gov.br/reflora/floradobrasil/FB23007.

Guerra, L. R. (2016). Avaliação da capacidade preditiva de carcinogenicidade e mutagenicidade de modelos in silico gratuitos para compostos orgânicos voláteis. Ciências e Biotecnologia. Dissertação de Doutorado, Universidade Federal Fluminense, Rio de Janeiro, Rio de Janeiro, Brasil. https://sucupira.capes.gov.br/sucupira/public/consultas/coleta/trabalhoConclusao/viewTrabalhoConclusao.jsf?popup=true\&id_trabalho=3611788.

Guilhermino, L., Diamantino, T., Silva, M. C. \& Soares, A. M. V. M. (2000). Acute toicity test with Daphnia magna: Na alternative to mammals in the Prescreening of Chemical Toxicity? Ecotoxicol Environ Saf, 46 (3), 357-362.

Hayder, N., Bouhlel, I., Skandrani, I., Kadri, M., Steiman, R., Guiraud, P., Mariotte, A.-M., Ghedira, K., Franca, M.-G. \& Ghedira, L. (2008). In vitro antioxidant and antigenotoxic potentials of myricetin-3-o-galactoside and myricetin-3-o-rhamnoside from Myrtus communis: modulation of expression of genes involved in cell defence system using cDNA microarray. Toxicology in vitro, 22(3), 567-581.

Herni, K., Subarnas, A., Diantini, A., \& Iskandar, Y. (2021). Cytotoxicity of Quercetin and Quercetin-3-O-rhamnoside of Etlingera elatior (Jack) RM Sm. leaves against HeLa Cervical Cancer Cells. Journal of Applied Pharmaceutical Science, 11(05), 085-090.

Horta, S. S. D. (2018). Interações medicamento-alimento: caracterização do conhecimento dos profissionais de saúde. Tese de Doutorado. Instituto Politécnico de Lisboa, Lisboa. Portugal. http://hdl.handle.net/10400.21/9338.

Irvine, J. D., Takahashi, L., Lockhart, K., Cheong, J., Tolan, J. W., Selick, H. E., \& Grove, R. (1998). MDCK (Madin-Darby Canine Kidney) Cells: A Tool for Membrane Permeability Screening. Journal of Pharmaceutical Sciences, 88 (1), 28-33.

Kozikowski, A. P., Tückmantel, W., Böttcher, G., \& Romanczyk, L. J. (2003). Studies in Polyphenol Chemistry and Bioactivity. 4.1 Synthesis of Trimeric, Tetrameric, Pentameric, and Higher Oligomeric Epicatechin-Derived Procyanidins Having All-4ß, 8-Interflavan Connectivity and Their Inhibition of Cancer Cell Growth through Cell Cycle Arrest1. The Journal of organic chemistry, 68(5), 1641-1658.

Kuo, P. L. (2005). Myricetin inhibits the induction of anti-Fas IgM-, tumor necrosis factor- $\alpha$-and interleukin-1 $\beta$-mediated apoptosis by Fas pathway inhibition in human osteoblastic cell line MG-63. Life sciences, 77(23), 2964-2976.

Kuo, P. L., Hsu, Y. L., Lin, T. C., \& Lin, C. C. (2005). The antiproliferative activity of prodelphinidin B-2 3'-O-gallate from green tea leaf is through cell cycle arrest and Fas-mediated apoptotic pathway in A549 cells. Food and chemical toxicology, 43(2), 315-323.

Lee, K. W., Lee, H. J., Surh, Y. J. \& Lee, C. Y. (2003). Vitamin C and Cancer: Chemoprevention Reappraisal. Am J Clin Nutri, 78, $1074-1078$.

Lima, N. M., Santos, V. N. C. \& Porta, L. (2018). Quimiodiversidade, bioatividade e quimiossistemática do gênero Inga (Fabaceae): uma breve revisão. Revista Virtual Química, 10, 459-473.

Lipinski, C. A. (2004). Lead-and drug-like compounds: the rule of five revolution. Drug Discov Today Technol, 1 (4), 337-341.

Lokvam, J., Clausen, T. P., Grapov, D., Coley, P. D. \& Kursar, T. A. (2007). Galloyl Depsides of Tyrosine from Young Leaves of Inga laurina. Journal of Natural Products, 70, 134-136.

Lopes, A. A., Oliveira, A. M., \& Prado, C. B. (2002). Principais genes que participam da formação de tumores. Revista de biologia e ciências da terra, 2(2).

Martins, C. M. (2017). Prospecção fitoquímica e caracterização dos compostos bioativos de Inga laurina (Sw.) Willd (Fabaceae). Tese de Doutorado, Universidade Federal de Uberlândia, Uberlândia, São Paulo, Brasil. https://repositorio.ufu.br/handle/123456789/19563

Martins, C. de M., de Morais, S. A., Martins, M. M., Cunha, L. C., da Silva, C. V., Teixeira, T. L., Santiago, M. B., Aquino, F. J. T. de, Nascimento, E. A., Chang, R., Martins, C. H. G. \& Oliveira, A. de. (2020). Antifungal and cytotoxicity activities and new proanthocyanidins isolated from the barks of Inga laurina (Sw.) Willd. Phytochemistry Letters, 40, 109-120.

Martins, D. F. B. (2015). Efeitos dos fármacos enquanto xenobióticos presentes no ambiente aquático ao nível das alterações tecidulares reportadas em peixes por vários estudos de toxicologia ambiental. Dissertação de Mestrado. Universidade Fernando Pessoa, Porto, Portugal. http://hdl.handle.net/10284/5330.

Martins, J. (2019). Estudos de metabolismo e inibição enzimática in vitro de moléculas hidrofóbicas: avaliação de um produto natural e um complexo de rutênio. Tese de Doutorado, Universidade de São Paulo, São Paulo, São Paulo, Brasil. https://doi.org/10.11606/T.60.2019.tde-20092021-194834.

Matsuda, M., Rambert, J., Malvy, D., Lejoly-Boisseau, H., Daulouede, S., Thiolat, D., Coves, S., Vincendeau, P. \& Mossalayi, M. D. (2004). Quercetin induces apoptosis of Trypanosoma brucei gambiense and decreases the proinflammatory response of human macrophages. Antimicrobial agents and chemotherapy, 48(3), 924-929.

Milton, K. \& Jeness, R. (1987). Ascorbic acid contente of neotropical planta parts avaliable to wild monkeys and bats. Experientia, 43, 339-342. 
Mochiutti, E., Carvalho, A. L. S., Nascimento, A. E. S., Brasil, D. S. B. \& Martelli, C. (2019, julho). Estudo in silico do potencial farmacológico do óleo essencial dos componentes majoritários do cipó d'alho (adenocalymma alliaceum). Anais do Congresso Brasileiro de Engenharia Química em Iniciação Cientifica. Uberlândia, Minas Gerais, Brasil, 1.

Mutoh, M., Takahashi, M., Fukuda, K., Matsushima-Hibiya, Y., Mutoh, H., Sugimura, T., \& Wakabayashi, K. (2000). Suppression of cyclooxygenase-2 promoter-dependent transcriptional activity in colon cancer cells by chemopreventive agents with a resorcin-type structure. Carcinogenesis, 21(5), 959-963.

Possette, R. F. D. S. \& Rodrigues, W. A. (2010). O gênero Inga Mill. (Leguminosae - Mimosoideae) no estado do Paraná, Brasil. Acta Botanica Brasilica, 24, 354-368.

Rao, B. V., Ramanjaneyulu, K., Rambabu, T. \& Devi, C. B. T. S. (2011). Synthesis and antioxidant activity of Galloyltyrosine, derivatives from young leaves of Inga laurina. International Journal of Pharma and Bio Sciences, 2, 39-44.

Rabelo, R. L. (2018). Atividade antimicrobiana e antibiofilme de flavonois como agentes para aplicação endodôntica. Trabalho de Conclusão de Curso. Universidade Estadual Paulista, Araçatuba, São Paulo, Brasil. http://hdl.handle.net/11449/203978.

Raso, G. M., Meli, R., Di Carlo, G., Pacilio, M., \& Di Carlo, R. (2001). Inhibition of inducible nitric oxide synthase and cyclooxygenase-2 expression by flavonoids in macrophage J774A. 1. Life sciences, 68(8), 921-931.

Rocha, G.V. (2015). Cálculos de Potenciais de Superfície para Análise de Drogabilidade. Dissertação (Mestrado em Biologia Computacional e Sistemas). Instituto Oswaldo Cruz, Rio de Janeiro, Rio de Janeiro, Brasil. https://www.arca.fiocruz.br/handle/icict/26318.

Rodrigues, G. S., Avelino, J. A., Siqueira., A. L. N., Ramos, L. F. P \& Santos, G. B. (2021). O Uso De Softwares Livres Em Aula Prática Sobre Filtros Moleculares De Biodisponibilidade Oral De Fármacos. Quim. Nova, 44 (8), 1036-1044.

Sá, P. G. S. de, Guimarães, A. L., Oliveira, A. P. de, Filho, J. A. de S., Fontana, A. P., Damasceno, P. K. F., Branco, C. R. C., Branco, A. \& Almeida, J. R. G. da S. (2012). Fenóis totais, flavonoides totais e atividade antioxidante de Selaginella convoluta (Arn.) Spring (Selaginellaceae). Rev Ciên Farm Básica Apli, 33 (4), 561-566.

Santos, R. da. C. dos, Daniel, I. C., Próspero, D. F. A., \& Costa, C. L. S. da. (2018). Modificação molecular incremental: análise de parâmetros físico-químicos, farmacocinéticos e toxicológicos in silico de fármacos inibidores seletivos da recaptação de serotonina (ISRSs). Boletim Informativo Geum, 9 (2), 31 -38.

Silva, C da. (2021). Atividade antioxidante e citotóxica do extrato e frações das folhas de Syzygium malaccense em células de melanoma cutâneo. Dissertação de Mestrado. Universidade Tecnológica Federal do Paraná. Pato Branco, Paraná, Brasil. Disponível em: http://repositorio.utfpr.edu.br/jspui/handle/1/26506.

Silva, E. M., Souza, J. N. S., Rogez, H.; Rees, J. F., Larondelle, Y. (2007). Antioxidant activities and polyphenolic contents of fifteen selected plant species from the Amazonian region. Food Chemistry, Barking, 101, 1012-1018.

Silva, F. C. da. (2015). Desenvolvimento de modelos de QSAR para identificação de substratos e inibidores de CYP3A4. Dissertação de Mestrado, Universidade Federal de Goiás, Goiânia, Goiás, Brasil. Disponível em: http://repositorio.bc.ufg.br/tede/handle/tede/5266.

Sousa, J. D. S. D., Bastos, M. D. N. D. C \& Gurgel, E. S. C. (2011). O gênero Inga (Leguminosae-Mimosoideae) na Província Petrolífera de Urucu, Coari, Amazonas, Brasil. Rodriguésia(62), 283-297.

Tlili, H., Marino, A., Ginestra, G., Cacciola, F., Mondello, L., Miceli, N., Taviano, M. F., Najjaa, H. \& Nostro, A. (2019). Polyphenolic profile, antibacterial activity and brine shrimp toxicity of leaf extracts from six Tunisian spontaneous species. Natural product research, 35(6), 1057-1063.

Ushirobira, T. M. A. (2003). Estudo químico, avaliação microbiológica e toxicológica pré-clínica (aguda e subcrônica) de extratos de sementes de Paullinia cupana HBK var. sorbilis (Mart.) Duche (GUARANÁ). Disponível em: https://pesquisa.bvsalud.org/portal/resource/pt/lil-444422.

Vasconcelos, D. N. (2019). Estudo e aplicação de sondas moleculares baseadas em dicroísmo circular induzido para determinação de sítios de ligação em albumina e caracterização de agregados amilóides. Tese de doutorado. Universidade Estadual Paulista "Júlio de Mesquita Filho, Bauru., São Paulo, Brasil. Disponível em: http://hdl.handle.net/11449/181077.

Veber. D. F., Johnson, S. R., Cheng, H.-Y., Smith, B. R., Ward, K. W. \& Kopple, K. D. (2002). Molecular properties that influence the oral bioavailability of drug candidates. Journal of Medicinal Chemistry, 45 (12), 2615-2623.

Verruck, S., Prudencio, E. S. \& Silveira, S. M. da. (2018). Compostos Bioativos Com Capacidade Antioxidante E Antimicrobiana Em Frutas. Revista CSBEA, 4 (1), 111-124.

Vilar, J. A. (2021). Desenvolvimento galénico teórico de uma emulsão cutânea óleo em água contendo Artemisia campestris L.Dissertação (Mestrado em Tecnologia do Medicamento e de Produtos da Saúde). Escola Superior de Saúde do Instituto Politécnico do Porto, Cidade do Porto, Portugal. Disponível em: http://hdl.handle.net/10400.22/17542.

Vivot, E., Munoz, J. D., Cruanes, M. D., Cruanes, M. J., Tapia, A., Hirschmann, G. S., Martinez, E., Disapio, O. \& Gattuso, M., Zacchino. (2001). S. Inhibitory activity of xanthine-oxidase and superoxide scavenger properties of Inga verna subsp affinis. Its morphological and micrographic characteristics. Journal of Ethnopharmacology, 76(1), 65-71.

Vrijsen, R., Everaert, L., \& Boeyé, A. (1988). Antiviral activity of flavones and potentiation by ascorbate. Journal of General Virology, 69(7), 1749-1751.

Waterbeemd, H. V. de \& Gifford, E. (2003). ADMET in silico modelling: towards prediction paradise?. Nature reviews Drug discovery, 2(3), 192-204.

Yazdanian, M., Glynn, S.L., Wright, J. L. \& Hawi, A. (1998). Correlating partitioning and Caco-2 cell permeability of structurally diverse small molecular weight compounds. Pharm Res, 15 (9), 1490-1494.

Yee, S. (1997). In vitro permeability across Caco-2 cells (colonic) can predict in vivo (small intestinal) absorption in man - fact or myth. Pharm Res, 14 (6), $763-766$. 
Research, Society and Development, v. 11, n. 2, e24511225592, 2022

(CC BY 4.0) | ISSN 2525-3409 | DOI: http://dx.doi.org/10.33448/rsd-v11i2.25592

Zhang, C., Ma, Y., Zhao, Y., Hong, Y., Cai, S., \& Pang, M. (2017). Phenolic composition, antioxidant and pancreatic lipase inhibitory activities of Chinese sumac (Rhus chinensis Mill.) fruits extracted by different solvents and interaction between myricetin-3-O-rhamnoside and quercetin-3-Orhamnoside. International Journal of Food Science \& Technology, 53(4), 1045-1053.

Zucker, E. (1985). Hazard Evaluation Division Standard Evaluation Procedure: Acute toxicity test for freshwater Fish. Washington, USA: USEPA. Disponível de: https://ntrl.ntis.gov/NTRL/dashboard/searchResults/titleDetail/PB86129277.xhtml. 